\title{
EL TEATRO PARA NIÑOS COMO ESTRATEGIA DE CRIANZA PRÁCTICAS, PAUTAS Y CREENCIAS HETERONORMADAS
}

\section{THEATRE FOR CHILDREN AS AN UPBRINGING STRATEGY}

\author{
Heteronormative Practices, Guidelines and Beliefs \\ GERMÁn CASELLA / casellahav@gmail.com \\ Instituto de Historia del Arte Argentino y Americano. Facultad de Artes. \\ Universidad Nacional de La Plata. Argentina
}

Recibido 23/1/2020 | Aceptado 4/4/2020

\section{RESUMEN}

Se propone el teatro para niños como una estrategia de crianza en cuanto es parte de los esfuerzos políticos por incorporar al niño y a la niña a la comunidad cultural, que permiten la (re)producción social (Bourdieu, 2000). Resultará operativo, entonces, abordar el análisis de discursos teatrales para la infancia, entendidos como configuraciones sociales significativas en materia de identidad de género y de sexo. Por tanto, se arriesga una relación homóloga entre las prácticas de crianza y algunos aspectos del teatro analizado que posibilitan extraer una noción específica de infanciay la experiencia estético-escénica que esta genera. Finalmente, se reflexionará acerca de cómo las teatralidades poéticas platenses heterosexualizan la realidad simbólica infantil a través de discursividades adultocéntricas que terminan siendo generacionales y hegemónicas.

\section{PALABRAS CLAVE}

Teatro; infancias; géneros; estrategia; crianzas

\begin{abstract}
We propose children's theater as a rearing strategy as it is a political effort to incorporate the child into the cultural community, allowing social (re)production (Bourdieu, 2000). It will be of uppermost interest to get into theater discourse analysis for infancy, comprehended as significative social configurations in gender and sexual identities. Thus, we propose an homologous relation between rearing methods and some aspects of the theater in analysis that enables the extrapolation of a specific concept of infancy and the aesthetic-scenic experience it generates. Finally, we will peruse into how La Plata's theater poetics heterosexualize simbolic realities in infancy through adult-centric discourse that end up being generational and hegemonic in nature.
\end{abstract}

\section{KEYWORDS}

Theater; infancies; gender; strategy; raising 


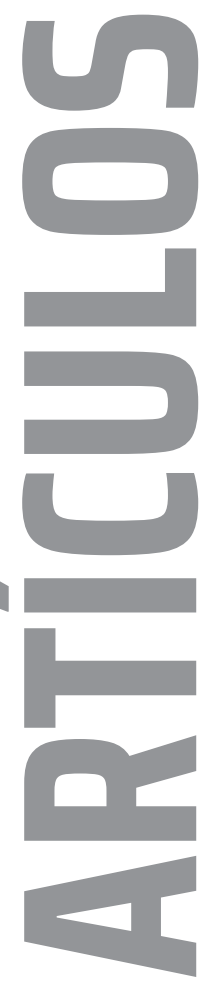

\section{«El control no debe entenderse como coacción, sino como medio destinado a reorientar las acciones del niño, logrando la inhibición de algunas tendencias y la estimulación de otras. En este sentido las prácticas de crianza facilitan la incorporación de los nuevos miembros, transmitiendo los valores y las formas de pensar y actuar esperados.» Eduardo Aguirre Dávila (2000)}

En este artículo se propone abordar el teatro para niños como una estrategia de crianza que regulariza identidades infantiles bajo parámetros heteronormados. Se tomará un corpus de obras de teatro para la infancia ${ }^{1}$ para reflexionar acerca de las discursividades sobre género y sexo que estas ponen en circulación. Así, se arriesgará que la figura de niño presente en dicho teatro es la de un espectador protoadulto heteronormado (Casella, 2019). Esta categoría permite recuperar las nociones y supuestos que atraviesan a las infancias que expectan y la consecuente conformación de identidades sexo-genéricas a través del análisis discursivo teatral. Se podrá acordar, mediante el estudio de casos, que se promueve una visión generacional de la infancia que tiende a cristalizar la norma heterosexual como naturalizada y vuelve obligatorio su tránsito y abordaje (Wittig, 2006). Por tanto, el teatro será pensado como una más de las instituciones que componen la infancia y, así, será parte de los esfuerzos por incorporar al cachorro humano en su comunidad cultural más próxima. Será, entonces, una estrategia de crianza en tanto se pueden encontrar una serie de «regularidades» (Bourdieu, 2000, p. 86) a lo largo del período analizado. Esto permite considerar el teatro infantil como inscripto al interior de un conjunto de prácticas de crianza cuya finalidad será la (re) producción de pautas sociales y culturales situadas que se tornan hegemónicas. Como se adelantó, estas se refieren a la promoción de vidas heterosexuales binarias que se ponen en circulación desde discursos teatrales regularizados.

Con el fin de demostrar tal hipótesis, se toman los aportes de Eduardo Aguirre Dávila (2000) respecto de las prácticas de crianza para generar indicadores de análisis en el teatro que se aborda. El autor divide el concepto de crianza en tres componentes - prácticas, pautas y creencias-, lo que permite generar un correlato metodológico para el análisis del teatro infantil por lo menos local. El primero se refiere a las prácticas de crianza, entendidas como las tecnologías, acciones y comportamientos regulados. Estos se relacionarán con las experiencias estéticas, encontrando en el análisis la constitución de un canon teatral que, como tal, sostiene parámetros regularizados por una idea evolutiva de la infancia.

1 Las mismas se desprenden de la tesis de maestría Teatro para niños y performatividad de género. El teatro infantil platense como estrategia de crianza heteronormada, dirigida por Dr. Gustavo Radice. Las unidades de análisis corresponden a obras presentadas en las temporadas de vacaciones de invierno del Centro Cultural Pasaje Dardo Rocha de la ciudad de La Plata (Buenos Aires, Argentina) entre los años 2011 y 2015. El corte cronológico está marcado por las diversas legislaciones argentinas aprobadas en el período que buscan la promoción de las diversidades e identidades disidentes. 


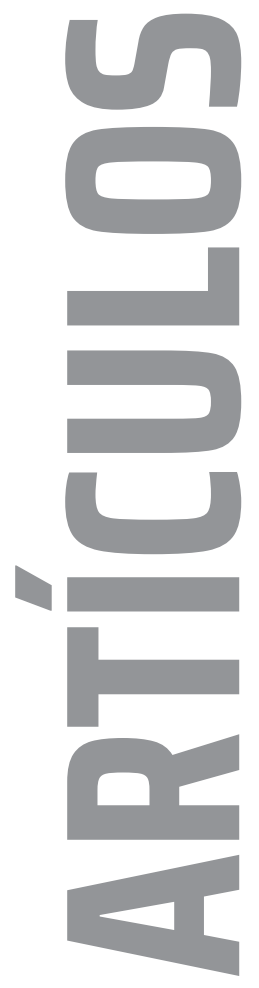

En segunda instancia, las pautas de crianza se referirán a lo esperado en la guía, normativas que se vuelven canon del actuar por lo que serán contrapuestas a las condiciones de enunciación de la infancia. Estas últimas actualizarán los géneros y las prácticas sexuales a partir de la reafirmación de habitus sexogenéricos mediante malas actuaciones de género (Butler, 1998). Por último, las creencias de crianza se presentarán como certezas compartidas que justifican el hacer, por lo que se relacionarán con las metas y visiones del mundo adulto. Se buscarán en los discursos las representaciones de adulto para concluir en que existe una estrategia narrativa regular que responde a la eliminación del plano de aquellos adultos que no responden a la norma heterobinaria.

Finalmente, un abordaje transdisciplinar de las infancias supone admitir que cada grupo social define a su niño (Carli, 2002) y, por tanto, sus propias estrategias de crianza. Estas últimas son las que otorgan significación a la categoría de niño a la que se asiste y establece sus consecuentes prácticas, pautas y creencias de crianza que se regularizan en su inscripción en una comunidad establecida. A tal fin, se retoma la categoría señalada al inicio de este artículo y se propone buscar en los discursos teatrales para la infancia platense las estrategias de crianza que regularizan al niño que asiste al teatro como un espectador protoadulto heteronormado.

\section{ESPECTADOR PROTOADULTO HETERONORMADO}

En principio, lo antedicho supone asumir que los campos que atraviesan la investigación -infancias, teatro, géneros y sexos- coinciden en que son formativos del sujeto sobre el que operan (Casella, 2018). Para ello deberá pensarse el discurso teatral a través de la Filosofía del teatro (Dubatti, 2007, 2012) cuya perspectiva de análisis entiende al teatro como acontecimiento. Como afirma Jorge Dubatti (2012), esto propone una zona de experiencia y subjetividad que «sienta un hito» (p. 25) en el devenir de la vida expectatorial. De este modo, se supera la visión semiótica del teatro para focalizar en su aspecto ontológico: el ser del teatro será su condición de organizador político-poético de la mirada. Se asume entonces que el teatro «es la zona de subjetividad resultante de estimulación y multiplicación recíproca de las acciones conviviales, poéticas [y] expectatoriales en relación de compañía» (Dubatti, 2007, p. 36). Así el acontecimiento teatral será un instaurador de subjetividades en tanto constituye una zona de experiencia modelizadora de lo relacional y lo identitario. Por tanto, la persona en situación de infancia que expecta será nombrada como espectador ${ }^{2}$ pues permite dar cuenta de la condición de acontecimiento del teatro y de productor de subjetividad.

2 También la masculinización de la palabra espectador como hegemónica permite denunciar la ausencia de perspectivas de género y diversidad que profundicen la mirada sobre las formas de ser niño, niña y niñe implicadas en este teatro. 


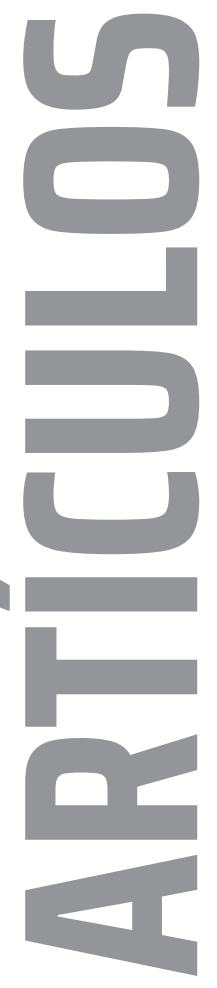

Por otro lado, durante la producción de poíesis teatral infantil se pondrán en circulación discursos teatrales que podrán ser abordados como configuraciones sociales significativas en cuanto, como define Sandra Carli (2002), el discurso será «terreno de constitución de los sujetos: los niños se constituyen en sujetos en la trama de los discursos [...]. Los discursos acerca de la infancia serán pensados como un lugar desde el cual se proponen modelos de identificación» (p. 29). Se destaca, así, que las discursividades al interior del teatro serán lo constitutivo de lo social, pues ponen en circulación modos de articular las identidades propuestas. En consecuencia, el discurso teatral para infancia funcionará como modelo de identificación por inaugurar un acontecimiento poiético que sienta formas específicas de estar en el mundo (Casella, 2018). Las representaciones discursivas implican una reconstrucción de la infancia desde una mirada adultocéntrica que, aunque con tensiones, priorizará una visión generacional y hegemónica sobre cómo transitar ese momento de la vida. A pesar de su acceso desigual, el teatro para niños será pensado como una más de las instituciones que componen la infancia, si se entiende por esta última al "conjunto de intervenciones institucionales que, actuando sobre el niño "real" [...] producen lo que cada sociedad Ilama niño. De modo que el niño [es] más bien un efecto de la infancia» (Diker, 2009, pp. 25-26). En efecto, una reinterpretación conceptual de la infancia permitirá superar visiones biologicistas que evitan el análisis político del impacto en aquellas intervenciones. Retomar a las infancias desde esta perspectiva implica reconocer que son constitutivas de un vínculo contingente y asimétrico, tal y como señala Eduardo Bustelo Graffigna (2012). Habrá una relación de subordinación y dependencia a partir de medirse su vida social infantil con una direccionalidad central: ser adulto. Epistemológicamente, esta postura implica apartarse del abordaje de la infancia evocada como generación y politizar la subjetividad infantil como «repetición» (Bustelo, 2012, p. 289). Por tanto, se sostiene al niño a través de la figura del "protoadulto: prioridad, preeminencia, superioridad adulta sobre la infancia. [Esto supone que] el telos de la infancia es su direccionalidad determinada para ser adulto» (Bustelo, 2012, p. 289). Es en esta linealidad que la exigencia de evocación y repetición es significante de aquel público infantil que se pretende determinador del acontecimiento. El espectador en situación de infancia podrá ser pensado como protoadulto en cuanto la visión adultocéntrica hegemoniza la realidad simbólica infantil siempre mediante abordajes generacionales y asimétricos. Asumir esto último permitirá visibilizar una serie de supuestos e hipótesis sobre el ser de la infancia que operan con centralidad durante la producción estético-escénica (Casella, 2019).

A la par, esta lectura supone que las intervenciones teatrales por parte del adulto productor guardan relación plena con la conformación de identidades sexogenéricas. Para ello, el género y el sexo deben ser abordados a través de la teoría de Judith Butler $(1998,2017,2018)$ sobre la concepción performativa del género. La autora entiende a los géneros como lo que responde a la práctica reiterativa 


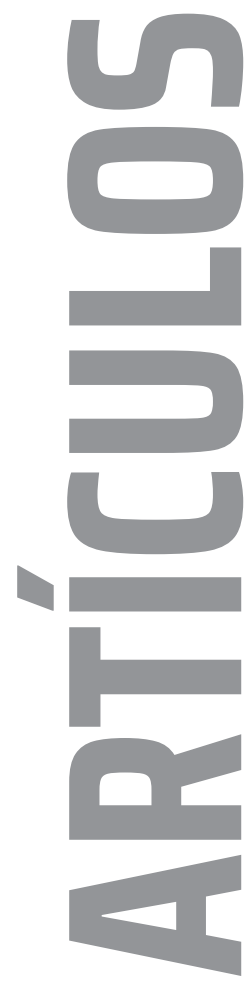

y referencial desde la que los discursos producen los efectos que nombran (Butler, 2017). Es una condición performativa que implica una necesidad de repetición de acción constante. Esto demuestra que el efecto sustantivo del género:

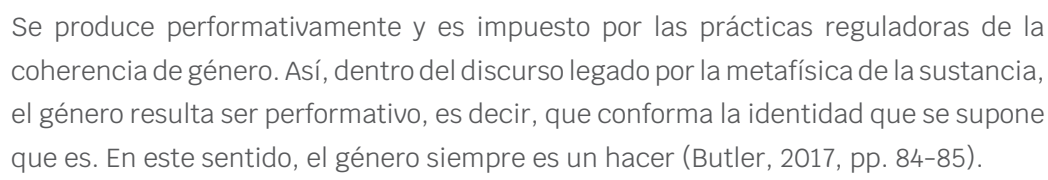

Por tanto, el género y el sexo serán identidades débilmente construidas con criterio de realidad únicamente cuando son actuadas. En consecuencia, la distinción binaria entre géneros será a partir de una «matriz heterosexual» (Butler, 2018, p. 24), es decir, una rejilla de inteligibilidad que des-historiza y des-sitúa aquella condición de acción performativa. A través de esta última como invocación a la cita, la heteronorma opera como reglamentación binaria del género. Entonces, las prácticas de deseo heterosexual se vuelven hegemónicas por ser ficciones reguladoras que naturalizan los modos identitarios. Así, el espectador infantil podrá pensarse como heteronormado en cuanto, como destaca Monique Wittig (2006), existe una relación social obligada basada en aquel binarismo de género resistente al análisis interpretativo. Habrá un núcleo de naturaleza que se vuelve ineludible: la relación heterosexual obligatoria que discursivamente niega «toda posibilidad de hablar si no es en sus propios términos y todo aquello que los pone en cuestión es enseguida considerado como "primario"» (Wittig, 2006, p. 49). De este modo, lo heterosexual no será una orientación sexual sino un régimen político basado en la sumisión cuya ideología oculta lo arbitrario de la categoría. Siendo así, se vuelve esperable que las narraciones sobre la infancia, constitutivas de la misma, promuevan la reducción a la heterosexualidad como norma obligada, convirtiéndola en hegemónica frente a otras expresiones de género y sexo. No debe olvidarse que el teatro para niños se actualiza, produce y reproduce a partir de la figura de niño espectador, a la par que este último se constituye como tal en relación dialéctica con el acontecimiento escénico (Casella, 2019). Podrá pensarse finalmente al espectador protoadulto heteronormado como uno cuyos espacios de experiencia teatral son marcados por hitos pautados, visiones adultas del mundo y, a su vez, al interior de una matriz de sexuaciones legitimadas y obligatorias. Este abordaje permitirá agudizar la mirada respecto de los mecanismos de representación y de los sentidos que circulan en el teatro analizado. Como una más de las instituciones que componen a la infancia como categoría, este teatro heterosexualiza la realidad simbólica infantil a través de discursos que tienen un funcionamiento performativo sobre el género y el sexo. 


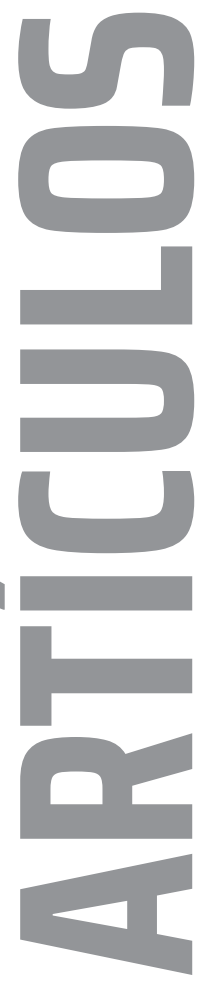

\section{EL TEATRO COMO ESTRATEGIA DE CRIANZA}

A partir de todo lo desarrollado se propone pensar al teatro para niños como una estrategia de crianza en cuanto es lo que permite la (re)producción social a partir de la puesta en valor de ciertas condiciones de existencia. La crianza será pensada como esfuerzo de determinación y medio de control de las acciones infantiles a través de una comunicación adulto-niño de los aspectos cotidianos (Aguirre Dávila, 2000). Así se encontrarán conductas repetibles, con cierta probabilidad de ocurrencia, que se vuelven patrón de expresión y aplicación por parte de los adultos. Esta conceptualización permitirá repensar al teatro para niños como un instaurador de pautas culturales acerca de cómo transitar y ser en la infancia. Esto, que incluye la dimensión sexo-genérica, funcionará como un modelo simbólico incorporado por actores sociales de manera subjetiva, lo que permite pensar a la cultura como actuada y a la vez vivida. Es operatorio entonces retomar la noción de habitus de Pierre Bourdieu $(2000,2007)$ como interiorización de las condiciones de existencia adquiridas durante los procesos de socialización. Se destaca de este concepto la presencia activa de experiencias pasadas, pues es "pasado que sobrevive en lo actual y que tiende a perpetuarse en el porvenir actualizándose en prácticas estructuradas según sus principios» (Bourdieu, 2007, p. 88). Esta condición de temporalidad estructurada del habitus es lo que permite abordar las prácticas de crianza como una estrategia, en el mismo sentido que Bourdieu la relaciona directamente con la (re)producción social. Existirán regularidades (Bourdieu, 2000) que permiten pensar una relación directa con aquella, si se considera el principio activo de la noción de práctica. ${ }^{3}$ Es entonces que se propone pensar al teatro para niños como una estrategia de crianza. De este modo, se lo podrá considerar como inscripto al interior de una serie de prácticas cuya finalidad, consciente o no, será la reproducción de las pautas sociales histórico y culturalmente situadas. Es decir que el teatro para niños será parte de la interiorización de las condiciones sociales de existencia en tanto es a la vez productor de las mismas.

De este modo, sostener al teatro para niños como una estrategia de crianza (heteronormada) supone un análisis de casos que permita rastrear el conjunto de prácticas por las que los agentes (re)producen sus condiciones de existencia. Se podrá encontrar la figura de niño como espectador protoadulto heteronormado en el teatro infantil platense a partir del análisis de los discursos de género y sexo que se abordan. Para ello, se buscará generar indicadores de análisis desde los

3 Pierre Bourdieu (2007) otorga a los agentes un «sentido práctico» (p. 92) que se origina en una complicidad ontológica entre el habitus y el mundo social e impide pensar en estructuras sociales que se autorreproducen. El paradigma de la estrategia entonces es entendido como desligado de proyectos autoconscientes, pues es el habitus lo que orienta objetivamente las prácticas de los agentes (Bourdieu, 2000). 


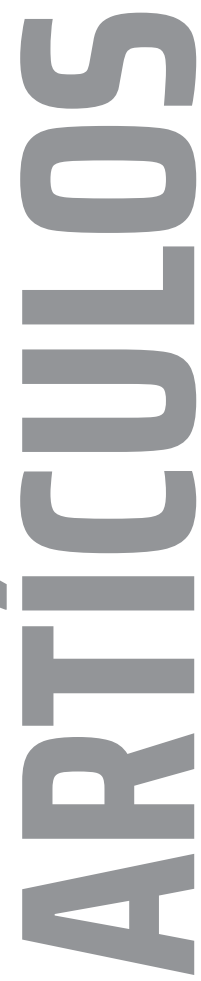

aportes de Aguirre Dávila (2000) respecto de las prácticas, pautas y creencias de crianza. Frente a estos se abordarán las unidades de análisis 4 a través de un correlato de los mismos con algunos aspectos del teatro para niños. Se propone, entonces, pensar por un lado a las prácticas de crianza como relacionadas con las experiencias estéticas. Por otro, a las pautas de crianza con las condiciones de enunciación de la infancia y, finalmente, a las creencias de crianza con las metas y visiones adultas.

\section{PRÁCTICAS, PAUTAS Y CREENCIAS DE CRIANZA}

En principio, las prácticas de crianza son entendidas como las acciones y los comportamientos regulados e intencionados que no solo garantizan la supervivencia del cachorro humano. También permiten la incorporación e interpretación del entorno a partir del uso de tecnologías específicas para tal fin. Siendo así, metodológicamente las prácticas de crianza habilitarán a revisar las experiencias estético teatrales para la infancia. Se arriesga que, si las prácticas de crianza responden a cómo se debe criar a los niños (Aguirre Dávila, 2000) entonces se podrá revisar todo aquello que sea modélico y pragmático en el teatro analizado. Esto implica un abordaje del acontecimiento desde la puesta en escena, entendida como los medios de interpretación escénica tales como la escenografía, la iluminación, la música, el trabajo actoral, entre otros (Pavis, 1998). De esta manera, se piensa a la experiencia estética como «el lugar exacto de la aparición del sentido de la obra teatral» (Pavis, 1998, p. 364). Entonces, como práctica de crianza, las puestas en escena develarán parte de las tecnologías y conductas repetibles que permiten la interpretación del mundo social a través de la experiencia poético-convivial (Dubatti, 2012).

Así, por ejemplo, se destaca que todos los casos basan sus dramaturgias en cuentos clásicos de la literatura universal o bien en reapropiaciones de los estudios Disney. Esto comprende la tendencia del teatro infantil de moverse en un terreno conocido para el mundo adulto (Mehl, 2010). La convocatoria familiar influirá en la selección de temas y contenidos y asegurará, mediante las fuentes citadas, una buena experiencia que conecta con la propia infancia del adulto. También garantiza la promoción de pretendidos valores universales a la par que resguarda las permisiones y prohibiciones del mundo simbólico infantil. Las visualidades de los vestuarios y escenografías circulan rondando lo ya transitado, pues aseguran

4 Las obras analizadas son: Seis actos y un prólogo para un cuento nuevo (2011), de Nahuel Aquino; La bella durmiente contada por una abuela $(2012,2014)$, Hansel y Gretel, un paseo por el bosque (2013), de Lorena Velázquez; Alicia en el País de las maravillas, una historia musical (Villagra, 2012, 2013), Aventuras y canciones del Gato con botas (Atencio, 2014), Aladdín... en una nueva aventura musical (Atencio, 2015), de Grupo Plan Ve; La doncella de la torre (2014), Oz, lo que ves no es lo que es (2015), de Gastón Cabrera; El gato en busca de botas... una aventura musical (Ventrice, 2015), de Grupo Inviernos Mágicos; S.O.S. Princesas al rescate (Vivier, 2015), de Grupo PIC. 


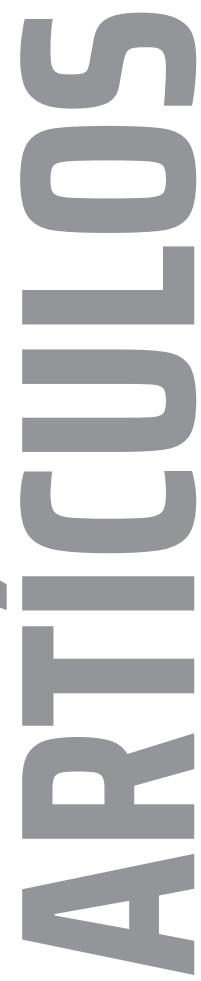

el reconocimiento de aquel universo simbólico según fórmulas ya probadas y aprobadas. A la par, cabe destacarse el protagonismo del teatro musical como lenguaje que se encuentra en todos los casos abordados. A excepción de S.O.S. Princesas al rescate (Vivier, 2015) — cuyas canciones pertenecen a las películas de Disney - todos los casos presentan música creada para el espectáculo. Esta tiende a ser enérgica y de pulso acelerado y se presenta en volúmenes altos que apoyan el uso de playback de los actores y las actrices. Esta última práctica corre para todos los casos a la vez que permite la realización por parte de los intérpretes de grandes destrezas coreográficas. A esto se suma la tendencia de estos a buscar la participación del público mediante palmas durante los cuadros musicales. Incluso existen casos en los que se exige a los espectadores una intervención mayor: respuestas a preguntas sobre la trama o directamente cantar junto con los personajes. Por ejemplo, se destacan los casos de Aladdín en una nueva aventura musical (Atencio, 2015) y Aventuras y canciones del Gato con botas (Atencio, 2014) en los que el tiempo ficcional de la obra se detiene para enseñar al público un verso de la canción. Esta exigencia de participación, presente en todos los casos, supone al niño que asiste al teatro como un «espectador temido» (Mehl, 2010, p. 22). Esto implica poner el acontecimiento en función del mero entretenimiento a la vez que habilita todo tipo de acciones que permitan capturar la atención. Así, la calidad del espectáculo estará medida por dos aspectos: el grado de compromiso o distensión que se logre con el niño que expecta y el mensaje pedagógico propuesto. Por un lado, el teatro infantil toma entidad de «fiesta» (Mehl, 2010, p. 23), donde estallan los colores y los atractivos visuales desde todos los frentes. Puede señalarse así la primacía de tonalidades vibrantes y cálidas que genera un abanico de colores relacionados entre sí. Esto se combina con actuaciones ampulosas que tienden a lo declamativo y a la forma. Además de la actuación, existe un supuesto desde la psicología evolutiva que produce la estetización de escenografías y utilerías que terminan por presentar un universo escénico-visual intervenido y suavizado.

Por otro lado, se produce una valorización del mensaje social por sobre la experiencia estética a través de la puesta en circulación de enseñanzas que se pretenden ahistóricas y universales. En la mayoría de los casos presentan una canción final donde se enfrascan las moralejas, reductibles a una serie de enunciados fácilmente reconocibles. ${ }^{5}$ Finalmente, si se piensa al objeto a través de las prácticas de crianza, entonces se acierta en que existiría un canon de representación estético en el teatro para niños. No debe obviarse que las prácticas de crianza «se constituyen en acciones con un patrón de expresión relativamente

5 Las enseñanzas puestas en circulación pueden nuclearse en pocos enunciados: el amor por sobre la diferencia de clase en La doncella de la torre (2014), El gato en busca... (2015), Aventuras y canciones del gato... (2014), Aladdin... (2015); no perder la fe en los sueños y la magia en Alicia en el país... (2013), Oz, lo que ves... (2015), S.O.S., Princesas... (2015); luchar contra lo que está mal en Hansel y Gretel... (2013) y Seis actos... (2011). 


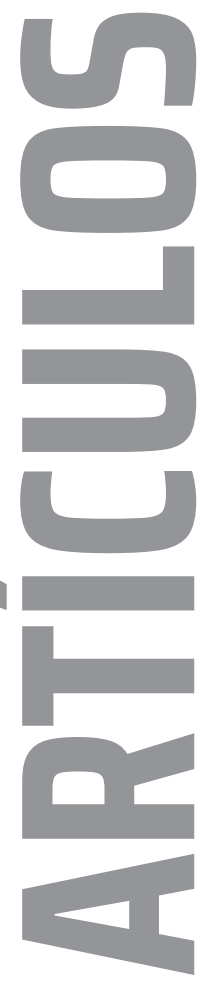

rígido que garantiza su aplicación de manera semejante por parte de los adultos de una comunidad de manera semejante» (Aguirre Dávila, 2000, p. 30). Siendo así, profundizar la mirada sobre las experiencias estéticas para la infancia permite encontrar constantes que serán producto no de una intencionalidad, sino un habitus orientador.

Se retoman entonces las pautas de crianza como lo esperado en la guía de las acciones hacia niños/as resultando en canon del actuar para con el crío. Son normativas establecidas y aceptadas como formas de contención social, por lo que se instituyen como lo esperable desde una representación colectiva de niño/a (Aguirre Dávila, 2000). Se propone pensar las pautas de crianza según las condiciones de enunciación de la infancia de los casos analizados, pues determinan un entramado de saberes sobre la infancia y sus limitaciones y posibilidades. De este modo, se focaliza no solo en los enunciados de la dramaturgia sino también en los de la puesta en escena (Pavis, 1998). Esto incluye la organización de materiales textuales y escénicos mediante interdependencias que surgen y se sostienen desde el espectáculo (Pavis, 1998, p. 136). Se propone entonces que la comprensión de la infancia establecida en los casos no admitirá otro tipo de identidad sexogenérica que no sea la heteronormada. A la vez se supone el devenir de la vida como cerrado y unívoco, al proponerse una realización completa y final en el pasaje a la vida adulta en situación de compañía sexoafectiva. Es a destacar que en todas las obras analizadas se plantea por lo menos una relación sexoafectiva monogámica entre parejas heterosexuales. Resalta el caso del Capitán Garfio de S.O.S... (Vivier, 2015) como quien introduce el conflicto en la trama al confundir a Lola, una nena, con su mamá generando situaciones de cortejo heteronormadas. Este caso destaca en cuanto, por un lado, no resiste a la convivencia varón/mujer sin una obligada vinculación afectiva y, por otro, roza la pedofilia sin grandes repercusiones. En el resto de los casos, la demanda y posterior obtención de un compañero/a sexoafectivo siempre es vista como objetivo de realización personal. Por ejemplo, en La bella durmiente... (Velázquez, 2014), la princesa berrinchuda Aurora es condenada a la heterosexualidad por esperar el beso de amor verdadero que en ningún momento se discute como diverso. Al ser despertada por el Príncipe, sus atributos de juventud se pierden instantáneamente y pasa a ocupar el lugar de una mujer ordenada y monarca.

Asimismo, la heterosexualidad protagónica incluye la promoción de tipos de masculinidad y femineidad que circulan discursivamente y así funcionan como lo esperado al interior de una pauta de crianza. En este sentido, puede arriesgarse que existe un protagonismo de ficciones regulativas fundadas en «actuar mal el propio género» (Butler, 1998, p. 311). Las contraposiciones definitorias de los géneros se sostienen en una serie de señalamientos (in)directos que parten de la presencia activa de experiencias pasadas, es decir, en el pretendido habitus de las infancias espectadoras. De este modo, se reproducen y actualizan feminidades 


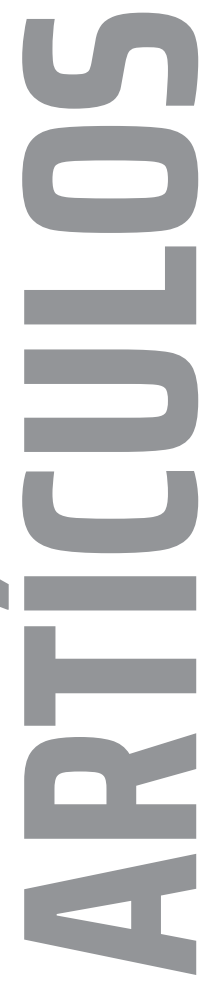

y masculinidades ya registradas en los esquemas de pensamiento y de percepción social. A la vez, estas afirmaciones se contraponen a disrupciones que no buscan tensionar el género, sino consolidar los modelos regulatorios. Por un lado, se encuentran las mujeres que reproducen sin cuestionamientos el género como cristalizado e indiscutido. Pero, por otro lado, el modelo de feminidad se ve torcido, generando una serie de sanciones como risas o sorpresas en el público infantil. Por ejemplo, Rapunzel de La doncella... (Cabrera, 2014) que es delicada y suave, descoloca con su acción de golpear a Febo con una sartén al invadir él su casa. Mismo caso de Aurora de La bella durmiente... (Velázquez, 2014) que en su visualidad responde a lo hegemónico tradicional, pero en su hacer y acción descoloca por su actitud necia. También Ailín, la princesa de El gato en busca... (Ventrice, 2015), es la generadora del conflicto familiar por pretenderse empoderada y negarse al mandato de su madre de casarse con quien no quiere. Todas estas actuaciones erróneas de lo femenino terminan por generar sanciones con formato de humor en el público infantil. En la misma línea, la representación de la masculinidad hegemónica también se retoma a partir de malas actuaciones que tienen como protagónico el desarrollo de normativas diversas. Estas siempre son una estrategia humorística y son exclusivas del universo de los varones a la par que suelen abrir la interpretación a la inmediata referencia homosexual. Se destaca el caso del Príncipe de La bella durmiente... (Velázquez, 2014) que usa una peluca rubia y eso le permite hacer un juego actoral con el flequillo que produce alarmas y miradas en el público y demás personajes. Este gesto feminizado, entre otros, es siempre producto de una demonización a la no representación heterobinaria desde su introducción como vehículo de humor.

Es entonces que se sostiene a lo femenino y lo masculino en este teatro infantil como fundado $-\mathrm{y}$ actualizado- en una serie de prácticas anteriores internalizadas. De este modo, las pautas de crianza entendidas como las condiciones de enunciación de la infancia en el teatro serán normatividades sobre los correctos modos de actuar los géneros. En ello cumplen un papel central los casos de travestismo en las obras analizadas para definir a las masculinidades. Se registran únicamente casos de actrices atribuidas mujeres que encarnan personajes varones y no así su contrario. De este modo, se proponen modos de ser masculinos desde la desnaturalización del género por imitación juzgada como ideal mismo (Butler, 2017). El travestismo, entonces, funciona como instaurador de emblemas de lo masculino mediante una serie de reafirmaciones de género (Butler, 2018). Estas incluyen el uso de prostéticos, como barbas en los casos de representación de varones adultos, $u$ otros medios actorales para disimular la condición cis genérica de las actrices. Pueden señalarse los gemelos de Alicia... (Villagra, 2013) donde el cabello largo de la intérprete se esconde tras un sombrero a la vez que una camisa ancha suaviza la presencia de sus pechos. También su actuación reafirma modos de ser niño varón, pues le otorga atributos de picardía y torpeza. Lo mismo sucede con la guardia real de los Naipes, que son señalados como varones y así las actrices 


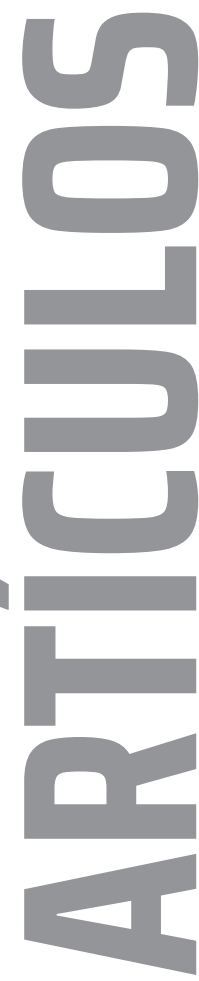

travestidas acentúan la condición de violentos y temerarios. Se propone entonces que las representaciones de lo binario son retomadas a partir de la actualización performativa del habitus infantil sobre cómo transitar los géneros. Es en este sentido que puede pensarse a las pautas de crianza como las condiciones de enunciación en un teatro como estrategia de crianza. Se constituye un sistema de códigos y principios interpretativos que promueven la conciencia colectiva sobre ese niño que expecta teatro.

Finalmente, el trinomio se completa con las creencias de crianza, entendidas como las certezas compartidas que justifican el accionar adulto (Aguirre Dávila, 2000). Como explicación, son lo que otorga sentido a las prácticas y pautas y vuelven naturalizables las formas de intervención. Por ello, se las relaciona con las metas y visiones adultas para analizar las discursividades, lo que incluye al texto dramático-espectacular como comprensible únicamente en su contexto social (Pavis, 1998). Se podrán contemplar así las representaciones de lo adulto que configuran valores compartidos sobre el futuro cívico social. La vinculación sexoafectiva heterosexual destacará como una serie de conocimientos prácticos acumulados en el tiempo, que se expresan en la promoción de valores pretendidos universales. Estos últimos, en el mismo sentido que las actuaciones erróneas del género, presentan como objetivo la eliminación del plano o la corrección de casos adultos que no reproducen el modelo de familia tradicional.

Puede señalarse al respecto el caso de la Madrastra de Hansel y Gretel... (Velázquez, 2013) como el que resume y potencia este valor: sin un nombre propio que la designe, genera risas y amenazas por no actuar según un sentimiento maternal para con sus hijastros. No responde a la tradición familiar patriarcal del mismo modo que no lo hace la Reina de Corazones de Alicia... (Villagra, 2013). Es una mujer grotesca que desentona con su diminuto marido, el Rey — representado por un títere-, y así se produce una torsión frente a los esperables de la vida matrimonial. Este desencuentro de tamaños implica una desprotección por parte del varón hacia la mujer, como lo pretendido ideal, y así la Reina es propuesta como desencajada por su poder político. El marido no será capaz de controlar a su esposa y esta se vuelve déspota y enceguecida, lo cual demoniza la figura de la mujer casada que acciona como soltera. Esta desrealización personal por la falta de coherencia para con los emblemas de género y la reproducción social mediante la presencia masculina se acentúa en la figura de las brujas. A excepción de Seis actos... (Aquino, 2011), todas las brujas son las villanas de las obras y, por tanto, son el elemento a superar o eliminar. Se interpretan como la figura adulta del fracaso y temor en el futuro, pues en su mayoría no son atractivas y son exclusivamente solteras. Esto introduce una serie de habilidades no valorizadas que terminan por ser invertidas ante la presencia de masculinidades hegemónicas. Por ejemplo, las tres brujas hermanas de Aladdin... (Atencio, 2015) son fácilmente engañadas por el príncipe al no conocer otras destrezas sociales más que las de su propia 


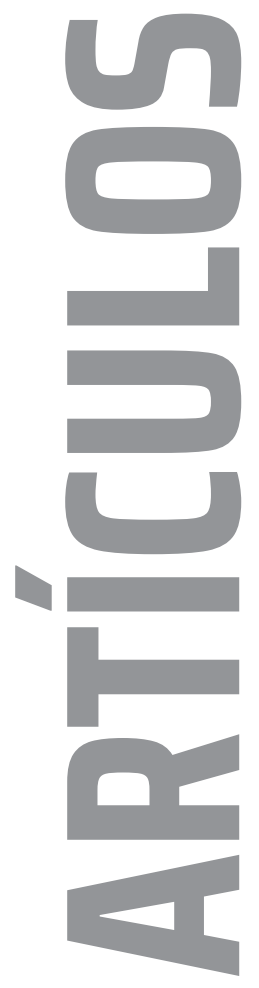

comunidad familiar. Mismo caso de la bruja de Hansel y Gretel... (Velázquez, 2013), que deformada por su condición de poderosa es fácilmente eliminada del plano al no conocer los hábitos ordenadores de una familia tradicional moderna. De este modo, se concluye que tanto las brujas como las mujeres que componen matrimonios disruptivos son entonces los sentidos de la futura vida adulta que no deben formar parte de los esperables.

Si en el teatro para niños existen metas y visiones sobre los adultos del mañana será porque estas expectativas se desprenden directamente de las creencias de crianza. Estas últimas son certezas compartidas que, a través de los casos analizados, pueden nuclearse en una fórmula concreta: el temor a la adultez que ha fracasado. Esto implica suponer la realización personal en un matrimonio heterosexual según parámetros de familia moderna, eliminando del plano a las figuras de adulto que no responden a la tradición hegemónica. Los sentidos que se otorgan son los de la constitución de un universo futuro ordenado, con las características de la idealidad propia de una comprensión generacional.

\section{A MODO DE CIERRE}

El teatro para niños propuesto como estrategia de crianza ha permitido el desarrollo de un análisis crítico en cuanto focaliza en las condiciones de (re)producción social del mismo. Entonces, se deduce que la figura de niño puede ser remitida como la de un espectador protoadulto heteronormado. Para ello se propusieron una serie de cruces entre los componentes de la crianza (Aguirre Dávila, 2000) y algunos aspectos del teatro infantil para conceptualizar las discursividades que se ponen en circulación. Así, se ha podido afirmar la promoción de realidades heterosexuales binarias como hegemónicas y autorizadas en una visión generacional de la infancia. Los análisis de casos construyen una serie de regularidades temporalizadas que permiten la reproducción social mediante una relación poetizada de pasadopresente-futuro. En este sentido, se podrá afirmar al teatro para niños como una estrategia de crianza, siendo que es una práctica regulada cuyos objetivos podrán o no ser conscientes. Por tanto, será necesaria la vigilancia epistemológica para generar una teoría del teatro para niños que pueda ser replicada mientras contempla condiciones de producción específicas.

\section{REFERENCIAS}

Aguirre Dávila, E. (2000). Socialización y prácticas de crianza. En E. Aguirre Dávila y E. Durán (Comps.), Socialización: prácticas de crianza y cuidado de la salud: un estudio con familias y niños que inician su escolarización en Santa Fe de Bogotá (pp. 19-92). Bogotá, Colombia: Universidad Nacional de Colombia.

Aquino, N. (15 de julio de 2011). Seis actos y un prólogo para un cuento nuevo [Obra de teatro]. La Plata, Argentina: Centro Cultural Pasaje Dardo Rocha. 


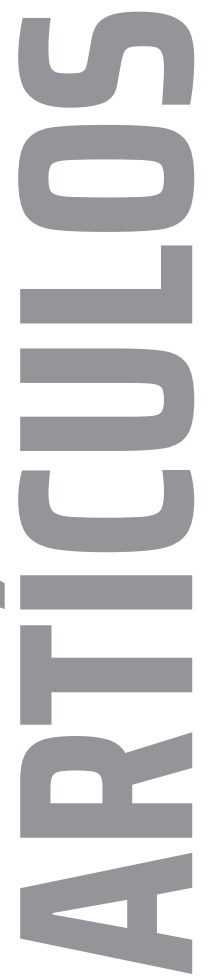

Atencio, R. (19 de julio de 2014). Aventuras y canciones del Gato con botas [Obra de teatro]. La Plata, Argentina: Centro Cultural Pasaje Dardo Rocha.

Atencio, R. (18 de julio de 2015). Aladdín en una nueva aventura musical [Obra de teatro]. La Plata, Argentina: Centro Cultural Pasaje Dardo Rocha.

Bourdieu, P. (2000). Cosas dichas. Barcelona, España: Gedisa.

Bourdieu, P. (2007). El sentido práctico. Ciudad Autónoma de Buenos Aires, Argentina: Siglo Veintiuno.

Bustelo Graffigna, E. (2012). Notas sobre infancia y teoría: un enfoque latinoamericano. Salud Colectiva, 8(3), 287-298. Recuperado de http://revistas.unla.edu.ar/saludcolectiva/ article/view/168

Butler, J. (1998). Actos performativos y constitución de género: un ensayo sobre fenomenología y teoría feministas. Debate Feminista, (18), 296-314. Recuperado de http://capacitacion.hcdn.gob.ar/wp-content/uploads/2015/12/actos-Buttler-1.pdf

Butler, J. (2017). El género en disputa. El feminismo y la subversión de la identidad. Barcelona, España: Paidós.

Butler, J. (2018). Cuerpos que importan: sobre los límites materiales y discursivos del "sexo». Ciudad Autónoma de Buenos Aires, Argentina: Paidós.

Cabrera, G. (24 de julio de 2014). La doncella de la torre [Obra de teatro]. La Plata, Argentina: Centro Cultural Pasaje Dardo Rocha.

Cabrera, G. (18 de julio de 2015). Oz, lo que ves no es lo que es [Obra de teatro]. La Plata, Argentina: Centro Cultural Pasaje Dardo Rocha.

Carli, S. (2002). Introducción. En Niñez, pedagogía y política. Transformaciones de los discursos acerca de la infancia en la historia de la educación argentina entre 1880 y 1955 (pp. 17-38). Ciudad Autónoma de Buenos Aires, Argentina: Miño \& Dávila.

Casella, G. (2018). Performatividad de género en el teatro para niños. Estrategias para el análisis de obras infantiles. Arte e investigación, (14), e003. doi: 10.24215/24691488e003

Casella, G. (agosto de 2019). Domesticar a través del teatro. El teatro para niños como estrategia de crianza (heteronormada). Ponencia presentada en las 9. Jornadas de Investigación en Disciplinas Artísticas y Proyectuales (JIDAP). Facultad de Artes de la Universidad Nacional de La Plata, La Plata, Argentina. Recuperado de http://sedici.unlp. edu.ar/handle/10915/81136

Diker, G. (2009). El discurso de la novedad. En ¿Qué hay de nuevo en las nuevas infancias? (pp. 11-31). Ciudad Autónoma de Buenos Aires, Argentina: Universidad Nacional de General Sarmiento.

Dubatti, J. (2007). Filosofía del teatro. Convivio, experiencia, subjetividad. Ciudad Autónoma de Buenos Aires, Argentina: Athuel.

Dubatti, J. (2012). Introducción a los estudios teatrales. Propuedéutica. Ciudad Autónoma de Buenos Aires, Argentina: Athuel.

Mehl, R. (2010). El teatro para niños y sus paradojas. Reflexiones desde la platea. Ciudad Autónoma de Buenos Aires, Argentina: Instituto Nacional del Teatro.

Pavis, P. (1998). Diccionario del teatro. Barcelona, España: Paidós.

Velázquez, L. (18 de julio de 2013). Hansel y Gretel, un paseo por el bosque [Obra de teatro]. La Plata, Argentina: Centro Cultural Pasaje Dardo Rocha. 


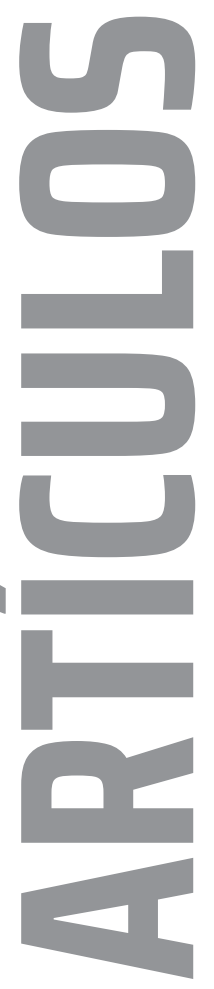

Velázquez, L. (14 de julio de 2014). La bella durmiente contada por una abuela [Obra de teatro]. La Plata, Argentina: Centro Cultural Pasaje Dardo Rocha.

Ventrice, G. (23 de julio de 2015). El gato en busca de botas... una aventura musical [Obra de teatro]. La Plata, Argentina: Centro Cultural Pasaje Dardo Rocha.

Villagra, L. (13 de julio de 2013). Alicia en el país de las maravillas, una historia musical [Obra de teatro]. La Plata, Argentina: Centro Cultural Pasaje Dardo Rocha.

Vivier, G. (28 de julio de 2015) S.O.S., Princesas al recate [Obra de teatro]. La Plata, Argentina: Centro Cultural Pasaje Dardo Rocha.

Wittig, M. (2006). El pensamiento heterosexual y otros ensayos. Madrid, España: Egales. 